\title{
Prevalence and distribution of oral health knowledge according to sociodemographic, behavioural and clinical characteristics in selected coastal districts of Tanzania
}

\author{
IRENE K. MINJA ${ }^{1^{*}}$, ANNE N. ASTROM² and JOYCE R. MASALU ${ }^{1}$ \\ ${ }^{1}$ Muhimbili University of Health and Allied Sciences, Department of Restorative Dentistry, School of \\ Dentistry, Dar es Salaam, Tanzania \\ Tanzania \\ ${ }^{2}$ University of Bergen, Bergen, Norway \\ , anne.aastrom@uib.no, jmasalu@muhas.ac.tz
}

\begin{abstract}
Background: Having knowledge about health issues is necessary for making informed decisions related to practicing lifestyles conducive to good health. The aim of this study was to identify socio-demographic, behavioural and clinical covariates of knowledge related to the cause and prevention of oral diseases among older adults in Tanzania.

Methods: A cross sectional household survey was conducted in two regions of Tanzania; Pwani and Dar es Salaam city. A total 1031 older adults aged 55 and above were personally interviewed, before undergoing a full mouth examination.

Results: the proportion of older adults with knowledge (total knowledge score $\geq 1$ ) on dental caries and gum disease was $14.9 \%$ and $2.3 \%$, respectively. Having low education level, belonging to a lower wealth quartile and lack of perceived need to see a dentist, were strongly associated with having no knowledge on dental caries. None of the covariates were significantly associated with knowledge on gum disease.

Conclusion: Knowledge on the two oral diseases is low among older adults interviewed. Factors associated with knowledge demonstrate substantial socio economic disparities. Development of policies and health education programs that target behavioural and socio economic determinants is recommended.
\end{abstract}

Key words: oral health, dental caries, gum disease, knowledge, adults, Tanzania

\section{Introduction}

According to the World Health Organization (WHO) (2002), the prevalence of older people is increasing probably due to improved standards of living resulting from better health care services, increased life expectancy and reduced fertility (Petersen \& Yamamoto, 2005). In the African continent, the number of elderly is expected to increase from 38 million to 212 million by 2050 (URT, 2003). This poses a concern especially in low-income countries where resources to care for the elderly are scarce. There is a large number of elderly living in rural areas, and most of them are living in dire poverty (URT, 2003). Efforts are therefore needed to curb the challenges of lack of vital infrastructure to care for the elderly.

In Tanzania, elderly people, 60 years and above, constitute about $5.5 \%$ of the population of about 45 million people (URT, 2013). Should the current economic setup in Tanzania remain unchanged, care for the elderly especially those residing in rural areas is likely to get worse. The global demographic transition with increased number of elderly accentuates the prevailing need for oral health care in this sub-group of the population. In most low income countries an increase in oral disease is expected owing to increase in consumption of sugary foods and lack of preventive services like use of fluorides (Ismail et al., 1997; Petersen, 2003).

Studies on oral health knowledge among older adults are rare although a few studies do report low levels of oral health knowledge, particularly so in the rural part of the

\footnotetext{
*Correspondence E-mail: ikminja@muhas.ac.tz
} 
older population (Varenne et al., 2006). Even in light of free oral health care, poor oral condition in terms of prevalent gingivitis and plaque accumulation have been reported in Tanzania (Kida et al., 2006). Furthermore, the prevalence of dental caries is high among older adults (Sarita et al., 2004). Most people who have dental problems would not attend dental clinics due to financial problems (Kikwilu et al., 2008). In high income countries, improved oral health has been reported in in terms of increased utilization of dental services, increased percentage of elderly with 20 or more teeth and reduced edentulousness (Petersen et al., 2005). These improvements have been attributable to established preventive oral health care programs such as fluoride use and reported increase in awareness on oral health issues that lead to most elderly preferring to retain their natural teeth.

According to the World Health Organization (WHO, 1998), it is important to achieve a level of knowledge, personal skills and confidence that are necessary for taking action to improve personal lifestyles and living conditions. Having poor understanding of prevention of dental diseases has been reported to be a risk indicator of poor self-and clinically assessed oral health status (Parker \& Jamieson, 2010; Jones et al., 2014; Wehmeyer et al., 2014). Furthermore, having knowledge on causative and preventive aspects of any disease is of vital importance as it helps populations make an informed decision when it comes to healthy living (Parker \& Jamieson, 2010; Wehmeyer et al., 2014). Moreover, an association has been reported between knowledge and oral health related quality of life (Divaris et al., 2011). Deficient knowledge on causes and prevention of oral diseases, contributes to people viewing their oral health as less important and therefore neglect seeking dental care. In addition, having knowledge about oral diseases is valuable for patients to contribute and agree on the suggested treatment plan and hence comply to the treatment provided (Holtzman et al., 2014; McQuistan et al., 2015).

Elsewhere, studies of oral health knowledge have shown that a sizeable proportion of elderly people have poor knowledge regarding causes and prevention of dental caries and gum disease (Lin et al., 2001; Zhu et al., 2005). The prevalence of poor knowledge has been found to be highest among older age groups in rural areas (Zhu et al., 2005). Moreover, low level of education and wealth status have been shown to relate to poor knowledge (Schwarz \& Lo, 1994; Lin et al., 2001). On the contrary, studies among older adults' dental patients in some developed countries, reported high knowledge score on oral health issues (McQuistan et al., 2015). Having lower level of knowledge is associated with old age; lower income and perceived poor oral health status (McQuistan et al., 2015). Studies among the elderly show that knowledge on oral health issues among elderly and their care givers, is pivotal part in determining their decayed, missing and filled teeth (DMFT) and periodontal status (Wårdh et al., 2002). Therefore, the importance of knowledge on causes and prevention of dental caries and periodontal diseases cannot be overemphasized.

It has been well proven that tobacco use in it's different forms is a risk factor for a number of oral diseases (Hanioka et al., 2011; Huang et al., 2012). Likewise, studies reveal an association between smoking and lack of knowledge on oral and general health issues (AlShammari et al., 2006; Sood et al., 2014). With regards to oral health related habits such as tooth brushing, studies reveal a deficient knowledge on oral health issues among those who brush irregularly (Wehmeyer et al., 2014). Assessing knowledge of older adults may assist the identification of risk factors for oral diseases which is beneficial in efforts to promote oral health. Although a number of studies have been conducted in Tanzania to assess oral health related knowledge in general terms (Masanja \& Mumghamba, 2004), few have specifically targeted knowledge regarding the causes and prevention of oral diseases among older adults (Åstrøm et al., 2009; Rwakatema et al., 2015). This study, therefore, aimed to determine socio-demographic, behavioural and clinical covariates of 
knowledge related to the cause and prevention of dental caries and periodontal diseases among older adults in selected rural and urban populations in coastal regions of Tanzania.

\section{Materials and Methods}

\section{Study area and design}

A cross sectional household survey was conducted in two regions of Tanzania, Pwani (constituting the rural communities of Kibaha and Bagamoyo Districts) and Dar es Salaam (constituting the urban community of Kinondoni District). A stratified (disproportionate) two-stage cluster sample design was utilized, with villages as primary sampling unit. 107 pure urban $(N=59,688)$ villages and 96 pure rural villages $(N=26,520)$ were listed in Kinondoni and in Kibaha/Bagamoyo, respectively. A sample size of 1,200 adults 50 years and above was calculated assuming a prevalence rate of tooth loss ( $\geq 1$ missing tooth) of $50 \%$, a precision of $4 \%$ and a design effect of 2 (Lwanga \& Lemeshow, 1991). This sample size was estimated utilizing tooth loss as an outcome variable, however in this study the outcome variable was knowledge on oral health issues.

At the first stage, 10 pure urban villages $(n=6,290)$ and 10 pure rural villages ( $n=$ 3,729 ) were selected by systematic random sampling from the district village population lists. At the second stage, a total of 60 households were selected by systematic random sampling from each village selected at the first stage. This involved randomly selecting the first household by spinning a bottle at the presumed centre of each village to obtain a starting direction, listing on papers all household heads in the selected direction up to the boarder of the village, folding the paper and randomly picking one name. The next household would be one whose front door was nearest to the previous one.

One person 50 years and above was enrolled per household. In case the household had several people in the targeted age group, one man and one woman were randomly selected. Over sampling of rural villages was implemented to achieve a sample size that was big enough to conduct stratified analyses. A village leader followed the data collectors through the village and traditional village protocol was observed ensuring a high response rate. Exclusion criteria were presence of disease/conditions that might pose a health risk to the participant or that may interfere with the interview and clinical examination.

\section{The questionnaire}

A structured interview schedule was constructed in English and translated into Kiswahili by two trained research assistants; and reviewed by oral health professionals for semantic, experiential and conceptual equivalence. The questionnaire included questions on sociodemographic variables (age, sex), residence (rural or urban), and family wealth as indicator of socio-economic status in accordance with a standard approach in equity analyses (Victora et al., 2005).

Questions regarding oral health knowledge on causes and prevention of dental caries and periodontal disease were included in the interview schedule. The participants were asked on the causes of tooth decay/gum diseases and their prevention. Depending on the stated cause and prevention of tooth decay / gum disease another variable was constructed to indicate the response as either 'correct' or 'not correct' with the score 0 and 1 , respectively. Furthermore, total knowledge score on dental caries and total knowledge score on gums disease, representing the sum of two knowledge items on dental caries and two knowledge items on gum disease, respectively were constructed ranging from 0-2. Oral health related behaviours were assessed by asking the participants whether they have attended a dentist in the past two years. Furthermore, a question as to whether or not they use tobacco of any form was included in the questionnaire. The participants were, as well, asked whether they perceived the need to see a dentist. The interview schedule was piloted before administration to identify questions that were not clear. The later was then 
administered in the field by two trained research assistants before the participants were clinically examined.

\section{Clinical examination}

One trained and calibrated dentist carried out all clinical examinations. Detailed description of clinical examination is described elsewhere (Kida et al., 2006). Plaque was recorded using mucosal-plaque score index (MPS) (Henriksen et al., 1999). The responses included four categories from score $1=$ no easily visible plaque, $2=$ hardly visible plaque, $3=$ moderate amount of plaque and $4=$ abundant $/$ confluent plaque. Dichotomization of the responses was done, whereby $0=$ none $/$ no easily visible plaque (scores 1 and 2 ) and $1=$ moderate $/$ abundant amounts of plaque (scores 3 and 4 ).

Full mouth dentition status examination was conducted and caries experience was assessed using World Health Organization criteria (WHO, 1997). A decayed tooth was recorded when a carious lesion was evident on visual inspection and / or on probing when necessary. Additionally, root tips were recorded as decayed teeth if there was a carious lesion. Absence of carious lesions on root tips, such as in erosion or trauma, the tooth was scored other respective options. Missing -component of the DMFT was recorded if there was a history of a cavity and / or painful tooth that led to extraction. The filled component was recorded if there was an intact permanent filling on a tooth. Total DMFT was dichotomized into $0=$ no decayed, missing or filled teeth and $1=$ having at least 1 DMFT. Intra examiner reliability was conducted and yielded a Kappa statistic of 1.0 for missing teeth due to caries and decayed teeth; as well as a Kappa value of 0.51 for plaque score (Kida et al., 2006).

\section{Data analysis}

Data were analysed using statistical package for social sciences - SPSS, version 23. Cross tabulation and Chi-square statistics were used to assess bivariate relationships. Factors associated with having no knowledge on causes and prevention of dental caries and gum disease were estimated by multiple logistic regression using the logit-model with $95 \%$ Confidence Interval given for the odds ratios indicating statistically significant relationship if both values were above or below 1 .

\section{Ethical considerations}

Research ethics clearance was provided by the Research and Publications Committee of Muhimbili University College of Health Sciences Ref. no. MU/RP/AEC/Vol. II/1; and from the Regional Committee for Medical Research Ethic in Western Norway (REK Vest no. 188.04). Further permission to carry out the study was provided by regional and district administration authorities; and village leaders. Informed consent was obtained from all participating subjects.

\section{Results}

A total of 511 (participation rate $85.2 \%$ ) urban and 520 (participation rate $86.7 \%$ ) rural subjects between 50 and 100 years (mean age: $62.9, \mathrm{SD}=10.6$; men: $46.4 \%$, no education: $44.7 \%$ ), underwent an extensive face to face interview. Internal consistency reliability of the two total knowledge scores was assessed to check whether the items measured the same construct. Cronbach's alpha of 0.845 and 0.735 were yielded for knowledge on dental caries items and knowledge on gum disease items, respectively. The Cronbach's alpha coefficients are above the recommended lower level of 0.70 (Streiner et al., 2014). 
Table 1: Socio-demographic, behavioural and oral health indicators among older adults in urban and rural Tanzania

\begin{tabular}{|c|c|c|c|c|}
\hline Variable & Response & Urban & Rural & p-value \\
\hline \multirow[t]{2}{*}{ Sex } & Male & $42.7 \%(218)$ & $50.0 \%(260)$ & 0.02 \\
\hline & Female & $57.4 \%(292)$ & $50.0 \%(260)$ & \\
\hline \multirow[t]{3}{*}{ Age } & 50-59 years & $50.3 \%(257)$ & $37.9 \%(197)$ & 0.00 \\
\hline & $60-69$ years & $28.8 \%(147)$ & $30.0 \%(156)$ & \\
\hline & $\geq 70$ years & $20.9(105)$ & $32.1 \%(167)$ & \\
\hline \multirow[t]{2}{*}{ Education } & None & $36.1 \%(184)$ & $53.4 \%(277)$ & 0.00 \\
\hline & Primary & $63.9 \%(325)$ & $46.6 \%(242)$ & \\
\hline \multirow[t]{4}{*}{ Wealth index } & $1^{\text {st }}$ quartile -least poor & $45 \cdot 5 \%(232)$ & $4.4 \%(23)$ & 0.00 \\
\hline & $2^{\text {nd }}$ quartile & $40.1 \%(205)$ & $8.8 \%(46)$ & \\
\hline & $3^{\text {rd }}$ quartile & $11.2 \%(57)$ & $35.0 \%(182)$ & \\
\hline & $\begin{array}{l}4^{\text {th }} \text { quartile -most } \\
\text { poor }\end{array}$ & $3.3 \%(17)$ & $51.7 \%(269)$ & \\
\hline \multirow{2}{*}{$\begin{array}{l}\text { Frequency of tooth } \\
\text { brushing }\end{array}$} & Seldom/Never & $28.2 \%(144)$ & $28.5 \%(148)$ & 0.49 \\
\hline & Daily & $71.8 \%(367)$ & $71.5(372)$ & \\
\hline \multirow{2}{*}{$\begin{array}{l}\text { Frequency of dental } \\
\text { attendance }\end{array}$} & Never attended & $78.9 \%(403)$ & $75.8 \%(394)$ & 0.23 \\
\hline & Attended $\geq 1$ & $21.1 \%(108)$ & $24.2 \%(126)$ & \\
\hline \multirow[t]{2}{*}{ Need to see a dentist } & No & $67.7 \%(346)$ & $52.1 \%(271)$ & 0.00 \\
\hline & Yes & $32.5 \%(165)$ & $47.9 \%(249)$ & \\
\hline Tobacco use & Yes & $15.1 \%(77)$ & $30.6 \%(159)$ & 0.00 \\
\hline No & No & $84.9 \%(434)$ & $69.4 \%(361)$ & \\
\hline \multirow[t]{2}{*}{ DMFT } & o DMFT & $13.7 \%(70)$ & $15.0 \%(78)$ & 0.31 \\
\hline & $\geq 1 \mathrm{DMFT}$ & $86.3 \%(441)$ & $85.0 \%(442)$ & \\
\hline \multirow[t]{2}{*}{ Plaque score } & Moderate /abundant & $44.1 \%(224)$ & $47.2 \%(244)$ & 0.17 \\
\hline & None/not visible & $55.9 \%(284)$ & $52.8 \%(273)$ & \\
\hline
\end{tabular}

Socio-demographic details, behavioural and oral health status indicators of older adults in urban (Kinondoni) and rural (Kibaha/Bagamoyo) show statistically significant differences of these two communities in a number of aspects. A significantly higher percentage of adults with lower education and those having a low wealth index reside in rural areas. Among participants living in rural areas a significantly higher percentage reported to have behaviours that are not conducive to oral and general health; including use of tobacco products and never attending to a dentist (Table 1).

Nineteen percent responded that they knew the causes of tooth decay. When probed further only two thirds (12.8\%) of them mentioned the correct causes of tooth decay. Similarly, among those who responded 'yes' on whether they had knowledge on prevention of dental caries (13.6\%), the ones who gave the right response were $11.3 \%$. When it comes to knowledge on causes of gum disease (4.8\%) and prevention of gum disease (3.2\%), more than half of them gave a wrong response when probed further (Table 2 ).

Table 2: Prevalence of knowledge on the different knowledge items among older adults

\begin{tabular}{|c|c|c|c|}
\hline Knowledge on: & $\begin{array}{l}\% \text { (n) Responded } \\
\text { 'YES' }\end{array}$ & $\begin{array}{l}\%(\mathrm{n}) \text { Correct } \\
\text { response }\end{array}$ & $\begin{array}{l}\%(n) \text { Incorrect } \\
\text { response }\end{array}$ \\
\hline Causes of dental caries & $19.1 \%(197)$ & $12.8 \%(132)$ & $6.3 \%(65)$ \\
\hline $\begin{array}{l}\text { Prevention of dental } \\
\text { caries }\end{array}$ & $13.6(140)$ & $11.3 \%(117)$ & $2.3 \%(23)$ \\
\hline Causes of gum disease & $4.8 \%(49)$ & $1.6 \%(16)$ & $3.2 \%(33)$ \\
\hline Prevention of gum disease & $3.2 \%(33)$ & $1.7 \%(18)$ & $1.5 \%(15)$ \\
\hline
\end{tabular}

The proportion of older adults with knowledge (total knowledge score $\geq 1$ ) on dental caries and gum disease was $14.9 \%$ and $2.3 \%$, respectively. Table 3 shows the percentage of older 
adults with no knowledge of dental caries (total knowledge score $=0$ ) according to sociodemographic, behavioural and clinical factors as well as the corresponding unadjusted odds ratios (OR) from binary logistic regression analysis. Rural residents $(O R=4.0,95 \% \mathrm{Cl}$ : 2.7-5.9 $\mathrm{p}<0.01$ ); those of older age group ( $\mathrm{OR}=2.1,95 \% \mathrm{Cl}: 1.4-3.2$ and $\mathrm{OR} 4.0,95 \% \mathrm{Cl}: 2.4-6.8$ $[p<0.01]$ for age groups 60-69 and 70+, respectively) were significantly more likely to have no knowledge on dental caries. Furthermore, having no knowledge on dental caries was associated with having lower level of education ( $\mathrm{OR}=5.9,95 \% \mathrm{Cl}: 4.0-8.7)$. As compared to those belonging to the least poor wealth quartile, those belonging to the poorest wealth quartile had higher odds of having no knowledge on dental caries, with OR of 2.2,95\% Cl:1.4$3.3,6.5,95 \% \mathrm{Cl}: 3.7-11.5$ and $9.8,95 \% \mathrm{Cl}: 5 \cdot 3-18.1$ for the $2^{\text {nd }}, 3^{\text {rd }}$ and $4^{\text {th }}$ quartile, respectively.

Older adults who reported to use tobacco in different forms including were also more likely than non-users to have no knowledge on dental caries ( $\mathrm{OR}=2.5,95 \% \mathrm{Cl}: 1.5-4.2)$. They were, as well, more likely to have moderate/abundant dental plaque $(\mathrm{OR}=1.5,95 \% \mathrm{Cl}$ : 1.1-2.2). They were less likely to perceive need to see a dentist ( $\mathrm{OR}=0.7,95 \% \mathrm{Cl}: 0.5-0.9)$. Knowledge on dental caries among these older adults did not show statistically significant difference by sex, dental health behaviours such dental attendance patterns and frequency of tooth brushing; as well as clinically detected decayed, missing and filled teeth (DMFT score). Besides, low frequency of tooth brushing showed likelihood of having no knowledge on dental caries (Table 3).

Table 3: Factors associated with no knowledge on dental caries (knowledge score $=0$ ) and gum disease (Knowledge score $=0$ ). Bivariate analysis: Chi Square, unadjusted odds ratios (OR) and $95 \%$ confidence interval $(\mathrm{Cl})$

\begin{tabular}{|c|c|c|c|c|c|}
\hline & & \multicolumn{4}{|c|}{$\begin{array}{l}\text { Percentage of older adults with total knowledge score of } \geq 1 \\
\text { on: }\end{array}$} \\
\hline & & $\begin{array}{l}\text { Dental caries } \\
\%(n)\end{array}$ & $\begin{array}{l}\text { OR } \\
(95 \% \mathrm{Cl})\end{array}$ & $\begin{array}{l}\text { Gum disease } \\
\%(\mathrm{n})\end{array}$ & $\begin{array}{l}\text { OR } \\
(95 \% \mathrm{Cl})\end{array}$ \\
\hline \multirow[t]{2}{*}{ Residence } & Urban & $76.9 \%$ (393) & $1 * *$ & $99.2 \%(506)$ & 1 \\
\hline & Rural & $93.1 \%(484$ & $4.0(2.7-5.9)$ & $98.0 \%(500)$ & $0.4(0.1-1.3$ \\
\hline \multirow[t]{2}{*}{ Sex } & Male & $84.5 \%(404)$ & 1 & $97.9 \%(461)$ & $1^{\#}$ \\
\hline & Female & $85.5 \%(473)$ & $1.1(0.8-1.5)$ & $99.3 \%(545)$ & $2.9(0.9-9.5)$ \\
\hline \multirow[t]{3}{*}{ Age } & 50-59 years & $78.0 \%(354)$ & $1 * *$ & $98.4 \%(444)$ & 1 \\
\hline & $60-69$ years & $88.1 \%(267)$ & $2.1(1.4-3.2)$ & $99.0 \%(295)$ & $1.6(0.4-6.0)$ \\
\hline & $\geq 70$ years & $98.4 \%(256)$ & $4.0(2.4-6.8)$ & $98.5 \%(267)$ & $1.1(0.3-3.6)$ \\
\hline \multirow[t]{2}{*}{ Education } & Primary & $71.4 \%(285)$ & $1 * *$ & $98.2 \%(388)$ & 1 \\
\hline & None & $93.7 \%(592)$ & $5.9(4.0-8.7)$ & $98.9 \%(618)$ & $1.6(0.6-4.6)$ \\
\hline \multirow[t]{4}{*}{ Wealth index } & $1^{\text {st }}$ quartile & $68.2 \%(174)$ & $1 * *$ & $98.8 \%(251)$ & 1 \\
\hline & $2^{\text {nd }}$ quartile & $82.5 \%(207)$ & $2.2(1.4-3.3)$ & $99.2 \%(248)$ & $1.5(0.2-8.9)$ \\
\hline & $3^{\text {rd }}$ quartile & $93.3 \%(223)$ & $6.5(3.7-11.5)$ & $98.7 \%(232)$ & $0.9(0.2-4.6)$ \\
\hline & $4^{\text {th }}$ quartile & $95.5 \%(273)$ & $9.8(5 \cdot 3-18.1)$ & $97.9 \%(275)$ & $0.5(0.1-2.2)$ \\
\hline \multirow{2}{*}{$\begin{array}{l}\text { Frequency of } \\
\text { tooth brushing }\end{array}$} & Daily & $83.8 \%(6.9)$ & $1^{\#}$ & $99.0 \%(724)$ & 1 \\
\hline & Seldom/Never & $88.4 \%(258)$ & $1.5(1.0-2.2)$ & $97.6 \%(282)$ & $0.4(0.1-1.1)$ \\
\hline \multirow{2}{*}{$\begin{array}{l}\text { Need for a } \\
\text { dentist }\end{array}$} & No & $87.2 \%(538)$ & $1 *$ & $98.9 \%(605)$ & 1 \\
\hline & Yes & $81.9 \%(339)$ & $0.7(0.5-0.9)$ & $98.3 \%(401)$ & $0.7(0.2-1.9)$ \\
\hline \multirow[t]{2}{*}{ Tobacco use } & No & $82.9 \%(659)$ & $1 * *$ & $98.9 \%$ (777) & 1 \\
\hline & Yes & $92.4 \%(218)$ & $2.5(1.5-4.2)$ & $97.9 \%(229)$ & $0.5(0.2-1.6)$ \\
\hline \multirow[t]{2}{*}{ DMFT } & o DMFT & $89.2 \%(132)$ & 1 & $97.3 \%(143)$ & 1 \\
\hline & $\geq 1 \mathrm{DMFT}$ & $84.4 \%(745)$ & $0.7(0.4-1.1)$ & $98.9 \%(863)$ & $2.5(0.7-7.8)$ \\
\hline \multirow[t]{2}{*}{ Plaque score } & None/not visible & $82.8 \%(461)$ & $1 *$ & $98.6 \%(545)$ & 1 \\
\hline & $\begin{array}{l}\text { Moderate } \\
\text { /abundant }\end{array}$ & $88.0 \%(412)$ & $1.5(1.1-2.2)$ & $98.7 \%(456)$ & $1.1(0.4-3.2)$ \\
\hline
\end{tabular}

*Significant at $\leq 0.05 ; * *$ Significant at $\leq 0.01 ;$ \#Significant in Chi-square statistics but lost the significance in bivariate logistic regression 
Chi-square statistics showed a higher percentage of female older adults $[1, \mathrm{~N}=1020)=$ 3.642, $p=0.05$ ], had no knowledge on gum disease (total knowledge score $=0$ ) (Table 3). This significance was lost when data was further subjected to binary logistic regression analysis. The knowledge score on gum disease failed to discriminate the participants when it came to their socio-demographic variables (i.e. place of residence, sex, age, education and wealth index); behavioural factors (i.e. frequency of tooth brushing, dental attendance frequency and tobacco use); as well as clinical indicators in terms of DMFT, and plaque scores. Furthermore, there was no statistically significant association between total knowledge score on gum disease and their perceived need to attend to a dentist (Table 3).

Table 4: Factors associated with no knowledge on dental caries (Knowledge score $=0$ ). Multivariate logistic regression: Chi Square, adjusted odds ratios (OR) and $95 \%$ confidence interval (Cl)

\begin{tabular}{|c|c|c|c|}
\hline \multicolumn{2}{|c|}{ Total Nagelkerke's $R^{2}=0.256$} & \multirow{2}{*}{$\frac{\text { OR }}{1}$} & \multirow[t]{2}{*}{$95 \% \mathrm{Cl}$} \\
\hline Residence: & Urban & & \\
\hline & Rural & 1.4 & $(0.8-2.7)$ \\
\hline \multirow[t]{3}{*}{ Age } & 50-59 years & 1 & \\
\hline & $60-69$ years & 1.4 & $(0.9-2.2)$ \\
\hline & $\geq 70$ years & 1.7 & $(1.0-3.2)$ \\
\hline \multirow[t]{2}{*}{ Education level } & Completed $1^{\circ}$ edu & $1 * *$ & \\
\hline & Not completed $1^{\circ}$ edu & 3.2 & $(2.1-4.9)$ \\
\hline \multirow[t]{4}{*}{ Wealth index } & $1^{\text {st }}$ quartile-leastpoor & $1 * *$ & \\
\hline & $2^{\text {nd }}$ quartile & 1.8 & $(1.2-2.8)$ \\
\hline & $3^{\text {rd }}$ quartile & 3.4 & $(1.7-7.0)$ \\
\hline & $4^{\text {th }}$ quartile-mostpoor & 4.1 & $(1.7-9.6)$ \\
\hline \multirow[t]{2}{*}{ Need to see dentist } & No & $1 *$ & \\
\hline & Yes & 0.6 & $(0.4-0.8)$ \\
\hline \multirow[t]{2}{*}{ Tobacco } & No & 1 & \\
\hline & Yes & 1.6 & $(0.9-2.9)$ \\
\hline \multirow[t]{2}{*}{ Plaque score } & None/no visible plaque & 1 & \\
\hline & Moderate /abundant plaque & 1.3 & $(0.9-1.9)$ \\
\hline
\end{tabular}

$*=$ Significant at $\leq 0.05 ; * *=$ Significant at $\leq 0.01$

Multiple logistic regression analysis was done to examine the relative contribution of sociodemographic-, behavioural- and oral health indicators-, to having no knowledge in dental caries (knowledge score $=0$ ) (Table 4). Variables that were included in the multivariate model were those that showed statistical significance in binary logistic regression analysis. In the final model, older adults with low level of education and those who belonged to the poorest wealth quartile were those most likely to present with no knowledge on dental caries. The corresponding ORs and $95 \% \mathrm{Cl}$ were (OR 3.2, 95\% $\mathrm{Cl} 2.1-4.9)$ and $4.1,95 \% \mathrm{Cl} 1.7-$ 9.6, respectively. Older adults who perceived a need to see a dentist were less likely compared to their counterparts to have no knowledge on dental caries (OR $0.6,95 \% \mathrm{Cl} 0.4$ 0.8 ). The total Nagelkerke's $R^{2}$ was 0.256 (model Chi square: 161.4; degrees of freedom (df) $=10, \mathrm{p}<0.000$ ).

\section{Discussion}

The study utilized data collected in a cross-sectional household survey among older adults in Tanzania. This approach may present a limitation as the information is obtained at one point in time. Furthermore, interview schedules are prone to recall- and social desirability bias. However, the knowledge scale utilized in this study, showed discriminative ability whereby having no knowledge in dental caries was associated with socio-economic variables, self-reported behaviours and health ratings in the expected direction. The sample size was estimated utilizing tooth loss as an outcome variable (Kida et al., 2006). It 
is unknown whether the present analysis using knowledge as outcome variable had enough statistical power and thus the strength of the associations might have been underestimated or even overestimated. Despite this, the data set provides information on many variables of a large sample size of "hard to reach individuals" that is worth to be reanalysed.

The demographic distribution of the urban / rural communities examined here, could be ascribed to poor access to health care facility and affordability of health services among the rural subjects, similar to what has been reported in other studies in Tanzania (Matee \& Simon, 2000; Åstrøm \& Masalu, 2001; Brinda et al., 2014) and elsewhere (Miura et al., 1997; Zhu et al., 2005). Moreover, a high proportion of older adults exhibiting moderate or abundant plaque, despite the reported high frequency of brushing, has previously been reported among Tanzanian population of different age groups; reflecting the probability of inadequate skills in performing effective tooth brushing (Nyandindi et al., 1994; Mumghamba et al., 2009). This is indicative of lack of oral health care to this group.

Although a substantial proportion of older adults responded to know the causes and prevention of dental caries and gum disease, they could not mention the correct answer upon further probing. This finding underscores the importance of having more than one item when measuring a construct, as many people may claim to have knowledge on health facts but in reality they may not possess the correct factual information. The most commonly mentioned causes of dental caries were sugary food items, a bug, a plant, tobacco, old age, heredity, luxury and pregnancy. It is imperative to note that there are still some misconceptions that dental caries is caused by things like bugs and some plants. Gingival diseases are easily prevented by good oral hygiene, however a substantial proportion still believes that these diseases can be caused by luxury, dirty blood, lack of vitamins and minerals as well as old age. As correctly stated elsewhere there are longstanding incorrect health beliefs on different health issues in communities which need to be corrected (Rwakatema et al., 2015). Dental health educators should instil correct oral health messages to assist people to make informed decisions in adopting health enhancing behaviours.

Oral health knowledge on the two common oral diseases, among older adults in Tanzania is quite low. A similar observation has been reported among a sample of mothers and primary school teachers in the Tanzania (Nyandindi et al., 1994; Petersen \& Mzee, 1998; Mwaiswelo \& Masalu, 2008). The prevalence in the current study is lower than that reported in China and Hong Kong among middle aged and elderly populations as (Lin et al., 2001; Schwarz \& Lo, 1994). Although the contexts are different, development of approaches to address knowledge gaps are recommended (Woolfolk et al., 1985; Åstrøm et al., 2009).

The finding that rural dwellers, as well as, those with lower level of education being at higher odds of having no knowledge on dental caries, supports findings observed among Tanzanian adults from previous studies (Sarita \& Tuominen, 1993; Kikwilu et al., 2008). This is due to the fact that urban subjects are more educated and have more access to information on health issues than their rural equivalents. Subsequently those with education are more likely to have more knowledge on health issues (Lin et al., 2001; Horowitz \& Kleinman, 2012; Johnston et al., 2015; McQuistan et al., 2015). Education level is also associated with socio-economic status and health outcomes (Ueno et al., 2012). Increasing odds of having no knowledge on dental caries with decreasing wealth quartile observed in this study corroborates with findings reported previously among Tanzanians, whereby, those belonging to lower socio-economic zones, perceived lack of knowledge of restorative care as barrier to receiving restorative treatment (Kikwilu et al., 2009). Similar association has also been reported among adults in Northern Ireland (Keogh \& Linden, 1991) and USA (McQuistan et al., 2015). Wealthy individuals are likely to afford information related items like radio, television and magazines (Kikwilu et al., 2009). Therefore, more 
emphasis should be put on placing services close to where people live especially in rural deprived areas.

The association between old age and 'having no knowledge' noted in this study, is similar to earlier reports in Tanzania that showed younger respondents were more likely to be knowledgeable than older respondents (Schwarz \& Lo, 1994; Lin et al., 2001; Kikwilu et al., 2008). Comparable findings on lack of association between dental attendance-, tooth brushing behaviour- and dental caries knowledge have been reported previously (Rayant, 1979; Jones et al., 2007). This contradicts studies done elsewhere, whereby, regular and recent dental visits were strongly associated with dental knowledge (Schwarz \& Lo, 1994; Wiener \& Shockey, 2014); and that those who brushed more frequently had higher knowledge scores (Lin et al., 2001).

Failure of dental attendance to predict knowledge on dental caries, among participants in this study, could be due to the evident reason for dental attendance pattern among the Tanzanian population being relief of pain that ends up with tooth extraction (Mosha \& Scheutz, 1993; Nyamuryekung'e et al., 2015). As also mentioned elsewhere, the only information that patients receive during emergency visits for tooth extraction concerns the post-operative care and not much on prevention of oral diseases (Kikwilu et al., 2009). Tobacco use in different forms was associated with having no knowledge on dental caries. The negative effects of tobacco use on oral health have been established (Reibel, 2003; Vellappally et al., 2007). This difference in knowledge could be due to the fact that those with knowledge are more conscious on their health and hence more aware of other health debilitating habits like smoking (Petersen \& Yamamoto, 2005).

The DMFT score, of the participants in this study was not associated with knowledge on dental caries. A systematic review by Berkman et al. (2011) has shown an association between low literacy on health issues and poor health outcomes. However, this was not observed among participants in this study. Knowledge is essential for someone to adopt healthy behaviour. Thus, these findings underscore the importance of knowledge on individuals' health related behaviours.

The final model on multivariate analysis shows an inter-linkage between low socioeconomic status, lack of education and placing least priority in expression on need for dental care. It has been shown for example, having information on health matters induces health seeking behaviour (Jones et al., 2007). This explicates the reason as to why older adults examined here did not perceive the need to see a dentist since they lacked correct information on dental caries. Dental caries is still the major reason for tooth loss even in this group of older adults (Kida et al., 2006). Efforts to improve older adults' oral health knowledge would improve their understanding of preventive care and enhance the need for preventive dental visits.

Lack of association between the different socio- behavioural- and clinical-variables, and gum disease is observed in this sample. Low knowledge regarding gum disease and particularly its relation to dental plaque has also been noted before (Nyandindi et al., 1994). Previous studies report a lack of correlation between correct knowledge about gum disease and related behaviours (Rayant, 1979); while others show a strong correlation between having knowledge on gum disease and disease outcomes (Wehmeyer et al., 2014). The Tanzania national ageing policy guides service delivery to the elderly, such that, elderly people are exempted from cost sharing for treatment. However, elderly people still have poor access to health care, and the type of care rendered is reported to be deficient and unstructured (URT, 2003). Therefore, efforts are required to reach out to this marginalized group.

The findings in this study signify the recommendation that, preventive - oriented oral health care systems should be planned, that include education and promotion of health related self-care practices. Oral health is an integral part of general health; dental caries and periodontal disease are the most common oral illnesses that exhibit high burden 
to community (Petersen \& Yamamoto, 2005). These diseases are lifestyle and behaviour related; and can be controlled and prevented by acquiring lifestyles that are conducive to health. Adequate information about the causes and how to prevent them have proven to be useful in prevention and lowering the disease burden. In conclusion, older adults in selected urban and rural areas of Tanzania have low level of knowledge on causes and prevention of dental caries and gum disease. Development of policies and health education programs that target behavioural and socio economic determinants is recommended for this group of population.

\section{Competing interests}

The authors declare that they have no competing interests.

\section{Authors' contributions}

IK conceived of the study, designed the study, collected data, statistical analysis, manuscript writing. AA: designed the study, statistical analysis, manuscript writing. JM participated in design of study, data collection and manuscript writing. All read and approved the final version of the manuscript.

\section{Acknowledgements}

This study was financially supported by the Faculty of Dentistry and the Centre for International Health, University of Bergen and Staten Lanakassen, Norway. The authors would like to thank the Local administrative authorities, Muhimbili University of Health and Allied Sciences, Tanzania and REK VEST of Norway, for giving permission to conduct this study.

\section{References}

Al-Shammari, K.F., Moussa, M.A., Al-Ansari, J.M., Al-Duwairy, Y.S. \& Honkala, E.J. (2006) Dental patient awareness of smoking effects on oral health: Comparison of smokers and non-smokers. Journal of Dentistry 34, 173-178.

Åstrøm, A.N., Jackson, W., Mwangosi, I.E.A. (2009) Knowledge, beliefs and behavior related to oral health among Tanzanian and Ugandan teacher trainees. Acta Odontologica Scandinavica 58, 11-18.

Astrøm, A.N. \& Kida, I.A. (2007) Perceived dental treatment need among older Tanzanian adults - a cross-sectional study. BMC Oral Health 7, 9.

Åstrøm, A.N. \& Masalu, J.R. (2001) Oral health behavior patterns among Tanzanian university students: a repeat cross-sectional survey. BMC Oral Health 1, 2.

Berkman, N.D., Sheridan, S.L., Donahue, K.E., Halpern, D.J. \& Crotty, K. (2011) Low Health Literacy and Health Outcomes: An Updated Systematic Review. Annals of Internal Medince 155, 97.

Brinda, E.M., Andrés, A.R., Andrés, R.A. \& Enemark, U. (2014) Correlates of out-of-pocket and catastrophic health expenditures in Tanzania: results from a national household survey. BMC Internationa Health and Human Rights 14, 5.

Divaris, K., Lee, J.Y., Baker, A.D. \& Vann, W.F. (2011) The relationship of oral health literacy with oral health-related quality of life in a multi-racial sample of low-income female caregivers. Health Quality of Life Outcomes 9, 108.

Hanioka, T., Ojima, M., Tanaka, K., Matsuo, K., Sato, F. \& Tanaka, H. (2011) Causal assessment of smoking and tooth loss: a systematic review of observational studies. BMC Public Health 11, 221. 
Henriksen, B.M., Ambjørnsen, E. \& Axéll, T.E. (1999) Evaluation of a mucosal-plaque index (MPS) designed to assess oral care in groups of elderly. Special Care in Dentistry 19, 154-157.

Holtzman, J.S., Atchison, K.A., Gironda, M.W., Radbod, R. \& Gornbein, J. (2014) The association between oral health literacy and failed appointments in adults attending a university-based general dental clinic. Community Dental and Oral Epidemiology 42, 263-270.

Horowitz, A.M. \& Kleinman, D.V. (2012) Oral health literacy: a pathway to reducing oral health disparities in Maryland. Journal of Public Health Dentistry 72 (Suppl 1), S26-30.

Huang, R., Li, M. \& Gregory, R.L. (2012) Effect of nicotine on growth and metabolism of Streptococcus mutans. European Journal of Oral Sciences 120, 319-325.

Ismail, A., Tanzer, J. \& Dingle, J. (1997) Current trends of sugar consumption in developing societies. Community Dental and Oral Epidemiology 25, 438-443.

Johnston, D.W., Lordan, G., Shields, M.A. \& Suziedelyte, A. (2015) Education and health knowledge: evidence from UK compulsory schooling reform. Social Science and Medicine 127, 92-100.

Jones, K., Parker, E.J. \& Jamieson, L.M. (2014) Access, literacy and behavioural correlates of poor self-rated oral health amongst an indigenous south Australian population. Community Dental Health 31, 167-171.

Jones, M., Lee, J.Y. \& Rozier, R.G. (2007) Oral health literacy among adult patients seeking dental care. Journal of American Dental Association 138, 1199-208.

Keogh, T. \& Linden, G. (1991) Knowledge, attitudes and behaviour in relation to dental health of adults in Belfast, Northern Ireland. Community Dent. Oral Epidemiology 19, 246-248.

Kida, I.A., Astrøm, A.N., Strand, G.V. \& Masalu, J.R. (2007) Chewing problems and dissatisfaction with chewing ability: a survey of older Tanzanians. European Journal of Oral Sciences 115, 265-274.

Kida, I.A., Astrøm, A.N., Strand, G.V., Masalu, J.R. (2006) Clinical and socio-behavioral correlates of tooth loss: a study of older adults in Tanzania. BMC Oral Health 6, 5.

Kida, I.A., Astrøm, A.N., Strand, G.V., Masalu, J.R. \& Tsakos, G. (2006) Psychometric properties and the prevalence, intensity and causes of oral impacts on daily performance (OIDP) in a population of older Tanzanians. Health Quality of Life Outcomes 4, 56.

Kikwilu, E., Frencken, J. \& Mulder, J. (2008) Utilization of toothpaste and fluoride content in toothpaste manufactured in Tanzania. Acta Odontologica Scandinavica 66, $293-9$.

Kikwilu, E.N., Frencken, J.E., Mulder, J. \& Masalu, J.R. (2009) Barriers to restorative care as perceived by dental patients attending government hospitals in Tanzania. Community Dental and Oral Epidemiology 37, 35-44.

Kikwilu, E.N., Masalu, J.R., Kahabuka, F.K. \& Senkoro, A.R. (2008) Prevalence of oral pain and barriers to use of emergency oral care facilities among adult Tanzanians. BMC Oral Health 8, 28.

Lin, H.C., Wong, M.C.M., Wang, Z.J., \& Lo, E.C.M. (2001) Oral Health Knowledge, Attitudes, and Practices of Chinese Adults. Journal of Dental Research 80, 1466-1470.

Lwanga, S. \& Lemeshow, S. (1991) Sample size Determination in Health Studies: a Practical Manual.

Masanja, I. \& Mumghamba, E. (2004) Knowledge on gingivitis and oral hygiene practices among secondary school adolescents in rural and urban Morogoro, Tanzania. International Journal of Dental Hygiene 2, 172-178.

Matee, M. \& Simon, E., 2000. Utilisation of dental services in Tanzania before and after the introduction of cost-sharing. International Dental Journal 50, 69-72.

McQuistan, M.R., Qasim, A., Shao, C., Straub-Morarend, C.L. \& Macek, M.D. (2015) Oral health knowledge among elderly patients. Journal of American Dental Association. 146, 
$17-26$.

Miura, H., Araki, Y., Haraguchi, K., Arai, Y. \& Umenai, T. (1997) Socioeconomic factors and dental caries in developing countries: a cross-national study. Social Science \& Medicine 44, 269-272.

Mosha, H.J. \& Scheutz, F. (1993) Perceived need and use of oral health services among adolescents and adults in Tanzania. Community Dental and Oral Epidemiology 21, 129132.

Mumghamba, E.G.S., Honkala, S., Honkala, E. \& Manji, K.P. (2009) Gingival recession, oral hygiene and associated factors among Tanzanian women. East African Medical Journal $86,125-132$.

Mwaiswelo, R.O. \& Masalu, J.R. (2008) Oral health Knowledge and behavior among pregnant women in Kyela District, Mbeya, Tanzania. Tanzania Dental Journal 14, 4752.

Nyamuryekung'e, K.K., Lahti, S.M., Tuominen, R.J., 2015. The relative patient costs and availability of dental services, materials and equipment in public oral care facilities in Tanzania. BMC Oral Health 15, 74.

Nyandindi, U., Palin-Palokas, T., Milén, A., Robison, V., Kombe, N. \& Mwakasagule, S. (1994) Participation, willingness and abilities of school-teachers in oral health education in Tanzania. Community Dental Health 11, 101-104.

Parker, E.J. \& Jamieson, L.M. (2010) Associations between indigenous Australian oral health literacy and self-reported oral health outcomes. BMC Oral Health 10, 3.

Petersen, P. (2008) World Health Organization global policy for improvement of oral health-World Health Assembly 2007. International Dental Journal 58, 115-121.

Petersen, P., Bourgeois, D., Ogawa, H., Estupinan-day, S. \& Ndiaye, C. (2005). The global burden of oral diseases and risks to oral health. Bull. World Health Organ. 83, 661-9.

Petersen, P. \& Mzee, M. (1998) Oral health profile of schoolchildren, mothers and schoolteachers in Zanzibar. Community Dental Health 15, 256-262.

Petersen, P.E., 2003. The World Oral Health Report 2003: continuous improvement of oral health in the 21st century - the approach of the WHO Global Oral Health Programme. Community Dentald and Oral Epidemiology 31, 3-24.

Petersen, P.E. \& Yamamoto, T. (2005) Improving the oral health of older people: the approach of the WHO Global Oral Health Programme. Community Dental and Oral Epidemiology 33, 81-92.

Rayant, G. (1979) Relationship between dental knowledge and tooth cleaning behavior. Community Dent. Oral Epidemiology 7, 191-194.

Reibel, J. (2003)Tobacco and oral diseases. Update on the evidence, with recommendations. Medical Principles and Practice 12 Suppl 1, 22-32.

Rwakatema, D., Ananduni, K., Katiti, V., Msuya, M., Chugulu, J. \& Kapanda, G. (2015) Oral health in nursing students at Kilimanjaro Christian Medical Centre teaching hospital in Moshi, Tanzania. BMC Oral Health 20, 23.

Sarita, P. \& Tuominen, R. (1993) Use of health care services in two rural communities in Tanzania. Community Dental and Oral Epidemiology 21, 133-5.

Sarita, P., Witter, D., Kreulen, C., Matee, M., van't Hof, M. \& Creugers, N., 2004. Decayed/missing/filled teeth and shortened dental arches in Tanzanian adults. International Journal of Prosthodontics 17, 224-30.

Schwarz, E. \& Lo, E.C.M. (1994) Dental health knowledge and attitudes among the middleaged and the elderly in Hong Kong. Community Dental and Oral Epidemiology 22, 358363.

Sood, P., Narang, R., Swathi, V., Mittal, L., Jha, K. \& Gupta, A. (2014) Dental patient's knowledge and perceptions about the effects of smoking and role of dentists in smoking cessation activities. European Journal of Dentistry 8, 216-23.

Streiner, D., Norman, G. \& Cairney, J. (2014) Health Measurement Scales: a Practical Guide to 
their Development and Use.

Ueno, M., Ohara, S. \& Inoue, M. (2012) Association between education level and dentition status in Japanese adults: Japan public health center-based oral health study. Community Dental Oral and Epidemiology 40, 481-7.

URT (2013) 2012 Population and Housing Census: Population Distribution by Administrative Areas. National Bureau of Statistics, Dar es Salaam, and Office of Chief Statistician, Zanzibar. March 2013

URT (2003) National Ageing Policy. Dar es Salaam, United Republic of Tanzania.

Varenne, B., Petersen, P.E., Ouattara, S., 2006. Oral health behaviour of children and adults in urban and rural areas of Burkina Faso, Africa. International Dental Journal 56, 61-70.

Vellappally, S., Fiala, Z., Smejkalová, J., Jacob, V., Somanathan, R., 2007. Smoking related systemic and oral diseases. Acta Medica Cordoba 50, 161-6.

Victora, C.G., Fenn, B., Bryce, J. \& Kirkwood, B.R. (2005) Co-coverage of preventive interventions and implications for child-survival strategies: Evidence from national surveys. Lancet 366, 1460-1466.

Wårdh, I., Berggren, U., Andersson, L. \& Sörensen, S. (2002) Assessments of oral health care in dependent older persons in nursing facilities. Acta Odontologica Scandinavica $60,330-6$.

Wehmeyer, M.M.H., Corwin, C.L., Guthmiller, J.M. \& Lee, J.Y., 2014. The impact of oral health literacy on periodontal health status. Journal of Public Health Dentistry $74,80-$ 7.

Wiener, R.C., Shockey, A.T., 2014. Oral health knowledge and dental visits in community living older adults in rural Appalachia-West Virginia: A cross-sectional analysis. Journal of Studies in Social Sciences 8, 1-14.

Woolfolk, M., Sgan-Cohen, H., Bagramian, R. \& Gunn, S. (1985) Self-reported health behavior and dental knowledge of a migrant worker population. Community Dental and Oral Epidemiology 13, 140-2.

WHO (2002) Active Ageing: A Policy Framework. World Health Organization.

WHO (1998) Health Promotion Glossary. World Health Organization.

WHO (1997) Oral Health Surveys : Basic Methods, 4th ed, 1997. World Health Organization.

Zhu, L., Petersen, P., Wang, H., Bian, J. \& Zhang, B., 2005. Oral health knowledge, attitudes and behaviour of adults in China. International Dentistry Journal 55, 231-241. 